\title{
A numerical experiment on the formation of the tropopause inversion layer associated with an explosive cyclogenesis: possible role of gravity waves
}

\author{
Shigenori Otsuka ${ }^{1 *}$, Megumi Takeshita $^{2}$ and Shigeo Yoden ${ }^{3}$
}

\begin{abstract}
The tropopause inversion layer (TIL) is a persistent layer with high static stability. Although some mechanisms for the formation of the TIL have been proposed, the time evolution of the TIL under realistic conditions especially when factoring in the contribution of small-scale processes such as gravity waves is not well understood. To gain an understanding of this factor, we conducted a numerical experiment on an explosive cyclogenesis in mid-latitudes using a nonhydrostatic regional atmospheric model. Although the TIL in the model is consistent with previous observations in the sense that it is stronger in the negative vorticity areas, the relationship is clear only in the development and mature stages of a cyclone, suggesting that the evolution of the cyclone plays an important role in the formation of the TIL. To ascertain the effects of gravity waves on the TIL, vertical convergence at the tropopause is analyzed. Histograms of maximum buoyancy frequency squared $\left(N_{\max }^{2}\right)$ within the TIL show that regions of vertical convergence have higher $N_{\text {max }}^{2}$ in addition to regions with high $\partial^{2} w / \partial z^{2}$, implying that waves having downward phase propagation also play an important role in the dynamical formation of the TIL. This tendency is clearer in regions of negative relative vorticity at the tropopause. By taking account of the fact that the gravity wave activities associated with the cyclone and the jet streak are enhanced during the development and mature stages of the cyclone, vertical convergence due to gravity waves associated with synoptic weather systems can be seen to be a key process in the formation of the negative correlation between the strength of the TIL and the local relative vorticity at the tropopause.
\end{abstract}

Keywords: Tropopause inversion layer; Extratropical cyclone; Gravity wave

\section{Background}

The tropopause inversion layer (TIL) is a layer with enhanced static stability just above the tropopause, and it has been extensively studied over the past decade (e.g., Birner et al. 2002; 2006). The TIL is observed at all latitudes from the tropics to the polar regions (e.g., Randel et al. 2007; Tomikawa et al. 2009; Son et al. 2011). The TIL exhibits a dependence on the relative vorticity around the tropopause, in that anticyclones exhibit substantially stronger inversion than cyclones (Zängl and Wirth 2002; Randel et al. 2007.

\footnotetext{
*Correspondence: shigenori.otsuka@riken.jp

1 RIKEN Advanced Institute for Computational Science, 7-1-26

Minatojima-minami-machi, Chuo-ku, 650-0047 Kobe, Japan

Full list of author information is available at the end of the article
}

This vorticity dependence has also been reproduced in idealized numerical simulations (e.g., Son and Polvani 2007). In general, two major mechanisms for TIL formation have been proposed: dynamical formation (e.g., Wirth 2003) and radiative formation (e.g., Randel et al. 2007; Randel and Wu 2010). Wirth (2003, 2004) applied a theory of conservative balanced dynamics to axisymmetric cyclonic and anticyclonic vorticies on a mid-latitude $f$ plane to explain the dependence of the TIL on vorticity. Idealized baroclinic life cycle experiments also support the formation of the TIL by dry dynamics (Wirth and Szabo 2007; Müller and Wirth 2009; Erler and Wirth 2011). Birner (2010) reported that a static stability forcing associated with stratospheric residual circulation represents the main cause for the zonal mean TIL in winter mid-latitudes. Erler and Wirth 2011 showed that wave

\section{照 Springer}

(c) 2014 Otsuka et al.; licensee Springer. This is an Open Access article distributed under the terms of the Creative Commons Attribution License (http://creativecommons.org/licenses/by/4.0), which permits unrestricted use, distribution, and reproduction in any medium, provided the original work is properly credited. 
breaking in baroclinic life cycle experiments is important for producing asymmetry between cyclonic and anticyclonic vorticies, resulting in net production of the TIL even in zonal mean statistics. As for radiative formation, Randel et al. 2007 performed one-dimensional radiative transfer calculations, in which strong gradients in both ozone and water vapor near the tropopause contribute to the formation of the TIL. Randel and Wu 2010 reported that the radiative influence of water vapor provides a primary mechanism for the summer inversion layer in the polar region. These formation processes depend on latitude and season; for example, dynamical formation is considered to be important in winter mid-latitudes, whereas radiative formation is dominant in polar summer (Birner 2010; Miyazaki et al. 2010b; Randel and Wu 2010).

In addition to these processes, Müller and Wirth (2009) stated that gravity waves, turbulence, and deep convection may be important for the formation of the TIL. Of these processes, however, the effect of gravity waves on the formation of the TIL is not well understood yet. Previous studies focused on idealized theories (Wirth 2003, 2004), and researchers performed numerical experiments using idealized systems (e.g., Erler and Wirth 2011; Müller and Wirth 2009; Son and Polvani 2007; Wirth and Szabo 2007), and analyzed them from a global point of view (e.g., Birner 2010; Miyazaki et al. 2010b; Randel et al. 2007). Thus, time-dependent smallscale processes around the TIL are not fully understood yet. Gravity wave activity around the TIL is considered to be important in terms of mixing. Miyazaki et al. 2010a reported that the degree of mixing around the TIL due to small-scale processes is high, and the local Richardson number tends to be less than 0.25 , indicating higher possibilities of gravity wave breaking around the TIL. Mixing around the tropopause leads to material exchange between the stratosphere and the troposphere.

Motivated by these studies, the objective of this work is as follows. The first question is how the TIL evolves in a realistic life cycle of an extratropical cyclone in winter mid-latitudes, in which dynamical formation mechanisms seem to be dominant. The second question is how smallscale processes such as gravity waves contribute to the TIL. To address these questions, a case study on a realistic explosive extratropical cyclogenesis is conducted using a mesoscale regional atmospheric model. Although this case study provides only limited statistics on the smallscale processes around the TIL, it will fill in the gap in previous studies.

The rest of this paper is organized as follows. The 'Methods' section describes the numerical model. The 'Results' section gives the results of the numerical experiment and analyses for the TIL. In the 'Discussion' section, implications of the results are discussed, and the 'Conclusions' section provides our conclusions.

\section{Methods}

The numerical model used in this study is the Japan Meteorological Agency Nonhydrostatic Model (Saito et al. 2006, 2007). We set up a single computational domain with a $20 \mathrm{~km}$ horizontal resolution. The domain has $207 \times$ 200 grid points centered at $39.0^{\circ} \mathrm{N}, 139.46^{\circ} \mathrm{E}$ on a Lambert projection. See Figure 1 for the coverage of the domain. The model employs a terrain-following coordinate system with 210 layers from the surface to $25 \mathrm{~km}$ above mean sea level. The vertical resolution is about $150 \mathrm{~m}$ around the tropopause. Model outputs are interpolated to pressure levels that have almost the same vertical grid spacing as that of the original data. Time integration is performed over $48 \mathrm{~h}$ from 0000 UTC 19 February, 2009 with a time step of $10 \mathrm{~s}$. During this period, an explosive cyclogenesis occurred around Japan.

The cumulus parameterization scheme is a modified Kain-Fritsch. The cloud microphysics scheme is a 6-class bulk microphysics. The GSM0412 radiation scheme (Yabu et al. 2005) and an improved Mellor-Yamada Level-3 planetary boundary layer scheme (Nakanishi and Niino 2004; 2006) are used. The time constant for the nonlinear diffusion term is $1,200 \mathrm{~s}$ and that for the linear diffusion term is $600 \mathrm{~s}$. The National Centers for Environmental Prediction (NCEP) Global Tropospheric Analyses (final analyses, FNL) with a horizontal resolution of $1^{\circ} \times 1^{\circ}$ and a time interval of $6 \mathrm{~h}$ are used as the initial and boundary conditions of the model.

Water vapor and ozone are important species for the radiative formation of the TIL as noted in the 'Background' section. In our experiment, water vapor is a prognostic variable in the model and contributes to the formation of the TIL. The ozone distribution is taken from three-dimensional monthly mean climatology interpolated in time and does not follow the temporal change of the local tropopause.

The two horizontal axes of the model domain are denoted by $x$ (almost eastward) and $y$ (almost northward). Note that the zonal wind $u$ in this paper denotes the wind component in the $x$ direction, and the meridional wind $v$ denotes that in the $y$ direction.

\section{Results}

\section{Synoptic evolution}

This subsection presents an overview of the cyclogenesis during the period of the experiment. Figure 1a,b,c,d,e shows the horizontal distributions of temperature (color) and geopotential height (contour) at $950 \mathrm{hPa}$ for the entire computational domain at 12 -h intervals. The explosive cyclogenesis is captured by this simulation as follows. At $t=12 \mathrm{~h}$, a cyclone starts to develop over Japan. The 


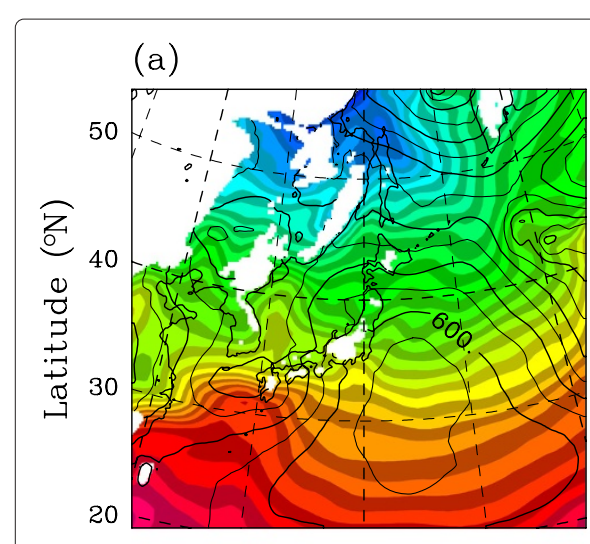

(d)

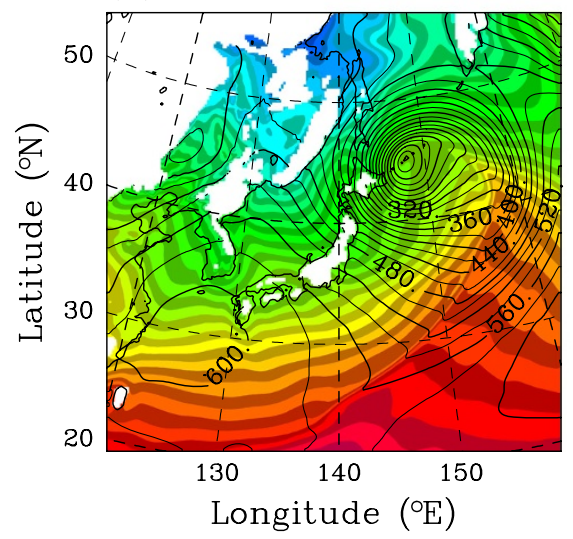

(b)

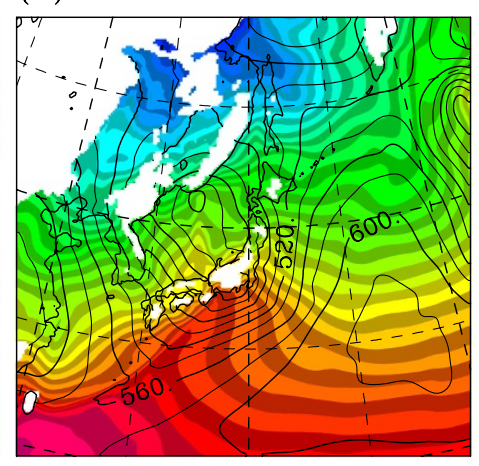

(e)

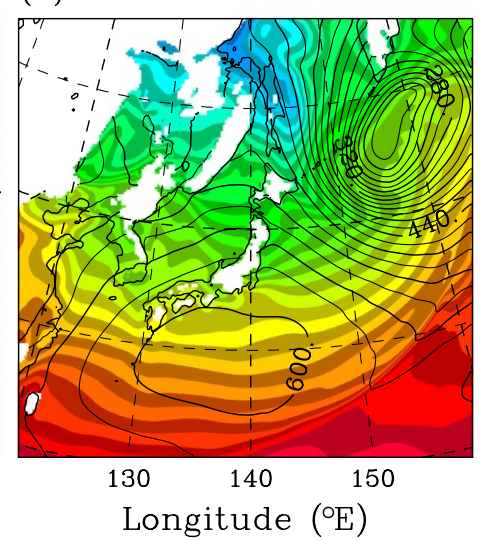

(c)

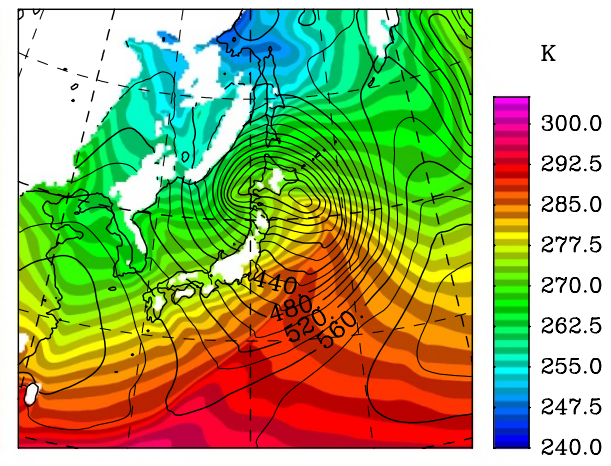

(f) Sea level pressure (hPa)

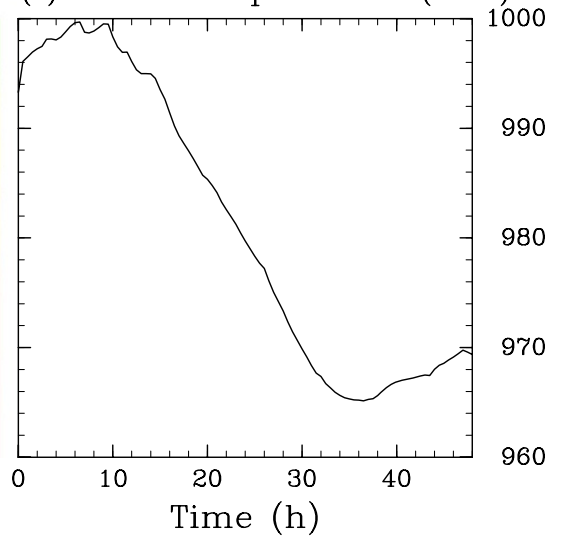

Figure 1 Temperature and geopotential height at $\mathbf{9 5 0} \mathbf{~ h P a}$. Horizontal maps of temperature (color) and geopotential height (contours) at 950 $\mathrm{hPa}$ for $t=\mathbf{( a )}$ 0, (b) 12, (c) 24, (d), 36, and (e) $48 \mathrm{~h}$. The white color denotes regions where the surface pressure is below $950 \mathrm{hPa}$. (f) Time series of minimum sea level pressure in the computational domain.

horizontal gradient of temperature becomes steeper, leading to frontogenesis. At $t=36 \mathrm{~h}$, the cyclone moves to the east of Hokkaido Island, at which time the central pressure drops to the lowest in the cyclone's life. At $t=48 \mathrm{~h}$, the cyclone moves to the east of the Kamchatka Peninsula, and the sharp core of the cyclone starts to decay. The model domain covers the cyclone throughout the period of the experiment. The domain also covers an anticyclone to the east of the cyclone until $t=24 \mathrm{~h}$ and another anticyclone to the west from $t=$ $24 \mathrm{~h}$. Asymmetry between the cyclone and the anticyclones is large; the cyclone is deeper and compact, and the anticyclones are wider. Although this asymmetry may create some bias in domain-averaged statistics on the TIL, the main purpose of the paper is to describe the time evolution of the TIL with fine-scale structures, and global or zonal mean statistics are beyond the scope of this study.

Figure $1 \mathrm{f}$ shows a time series of minimum sea level pressure within the computational domain. As the cyclone develops, the pressure starts to decrease from $t=10$ $\mathrm{h}$. The pressure becomes the lowest, $965 \mathrm{hPa}$, at around $t=36 \mathrm{~h}$ and then starts to increase. The pressure decreases nearly $35 \mathrm{hPa}$ in $24 \mathrm{~h}$ between 35 and $45^{\circ} \mathrm{N}$, which satisfies the criterion for a 'bomb' cyclone by put forward by Sanders and Gyakum (1980). As the position and the central pressure of the cyclone at $t=36 \mathrm{~h}$ are almost the same as those in the JMA analysis (Japan Meteorological Agency 2009), we consider that the model simulates the cyclone realistically. In this paper, we define the development stage of the cyclone as the period from 10 to $36 \mathrm{~h}$; its typical snapshot is at $t=24 \mathrm{~h}$, and the mature stage is at $t=36 \mathrm{~h}$.

Figure 2 shows vertical cross sections along $x=131$ in the model (almost meridional sections crossing the center of the surface cyclone) of the zonal wind ( $u$, color) and potential temperature ( $\theta$, contour) at $t=36 \mathrm{~h}$. The tropopause detected according to the definition by the World Meteorological Organization (WMO) is shown by the dots. The axis of the subtropical jet is located around $1,600 \mathrm{~km}$ from the southern boundary $\left(145^{\circ} \mathrm{E}, 35^{\circ} \mathrm{N}\right)$, $300 \mathrm{hPa}$. The center of the surface cyclone is located at $2,700 \mathrm{~km}\left(147^{\circ} \mathrm{E}, 44^{\circ} \mathrm{N}\right)$, where the zonal wind reverses. The tropopause is located above $100 \mathrm{hPa}$ at equatorward 


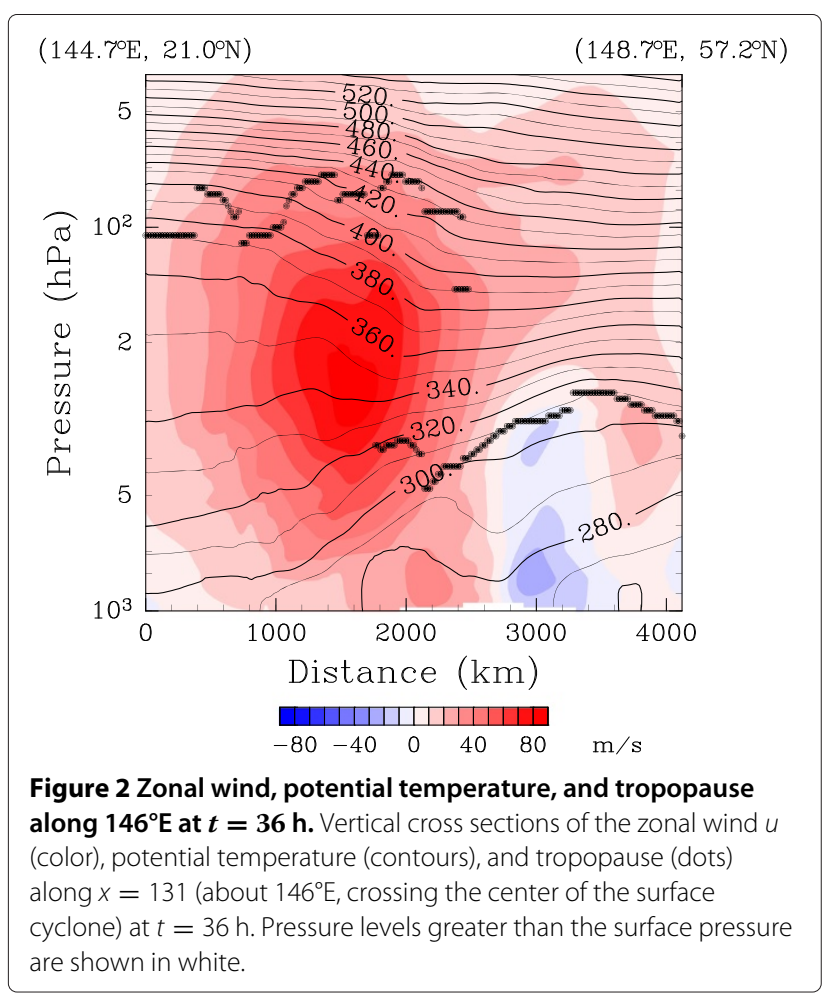

latitudes of about $45^{\circ} \mathrm{N}$, and around 300 to $500 \mathrm{hPa}$ at latitudes poleward of the jet. Near the jet, a multiple tropopause appears, exhibiting tropopause folding.

Figure 3a shows the horizontal distributions of the tropopause height according to the WMO definition $\left(Z_{\mathrm{TP}}\right.$, color) and the wind speed at $300 \mathrm{hPa}$ (contour) at $t=36$ h. When multiple tropopauses are detected at the same horizontal grid point, the lowest level is used in this plot. The contour line for $80 \mathrm{~m} \mathrm{~s}^{-1}$, which shows the jet axis, lies from $132^{\circ} \mathrm{E}, 32^{\circ} \mathrm{N}$ to $154^{\circ} \mathrm{E}, 38^{\circ} \mathrm{N}$. The gap of $Z_{\mathrm{TP}}$ is located around the jet axis, $Z_{\mathrm{TP}}>14 \mathrm{~km}$ to the south and $Z_{\mathrm{TP}}<14 \mathrm{~km}$ to the north. The lowest $Z_{\mathrm{TP}}$ appears around 140 to $150^{\circ} \mathrm{E}, 40$ to $45^{\circ} \mathrm{N}$, where the center of the surface cyclone is located. In the following analyses, only regions where $Z_{\mathrm{TP}}<14 \mathrm{~km}$ are used.

Figure $3 \mathrm{~b}$ shows the vertical component of relative vorticity at $Z_{\mathrm{TP}}$ (hereafter $\zeta_{\mathrm{TP}}$ ) at $t=36 \mathrm{~h}$. Horizontal winds at $Z_{\mathrm{TP}}$ are also shown by arrows. A spiral pattern of positive and negative vorticities associated with the cyclone is discernible. The highest $\zeta_{\text {TP }}$ is obtained around 145 to $150^{\circ} \mathrm{E}, 40$ to $45^{\circ} \mathrm{N}$, which is located to the north of the jet exit region and to the east of the surface cyclone. The lowest $\zeta_{\text {TP }}$ is obtained around 160 to $165^{\circ} \mathrm{E}, 45^{\circ} \mathrm{N}$. The region of $\zeta_{\mathrm{TP}}>0$ along the northern edge of the jet streak (southern edge of the analysis region) is caused by the horizontal wind shear of the jet streak. A spiral band of $\zeta_{\mathrm{TP}}>0$ extending to the northwestern corner of the domain coincides with the northeastern edge of strong westerlies at the tropopause level. Within the analysis region, the area of positive $\zeta_{\mathrm{TP}}$ is greater than that of negative $\zeta_{\mathrm{TP}}$. Thus, data are binned by $\zeta_{\text {TP }}$ and normalized by the sample size to ensure that the conclusions are not biased by the difference of positive and negative $\zeta_{\mathrm{TP}}$ areas.

\section{Relationship between TIL and relative vorticity at tropopause}

As previous studies reported the existence of a negative correlation between $\zeta_{\mathrm{TP}}$ and the strength of the TIL, we

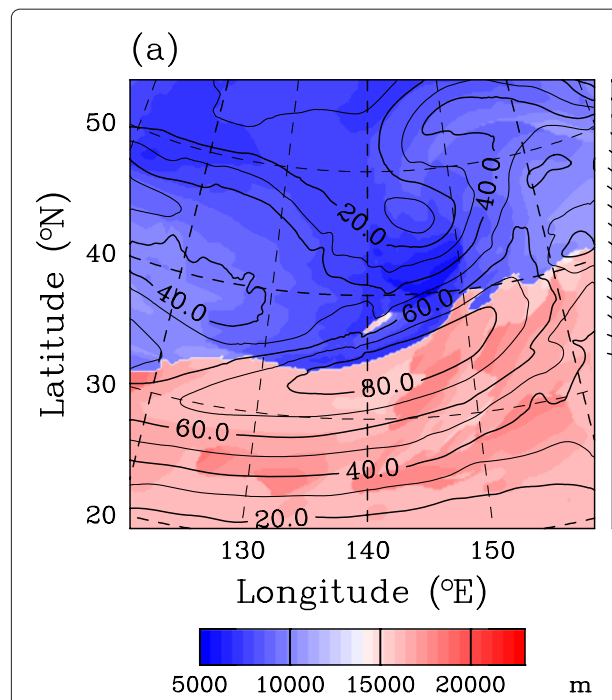

(b)

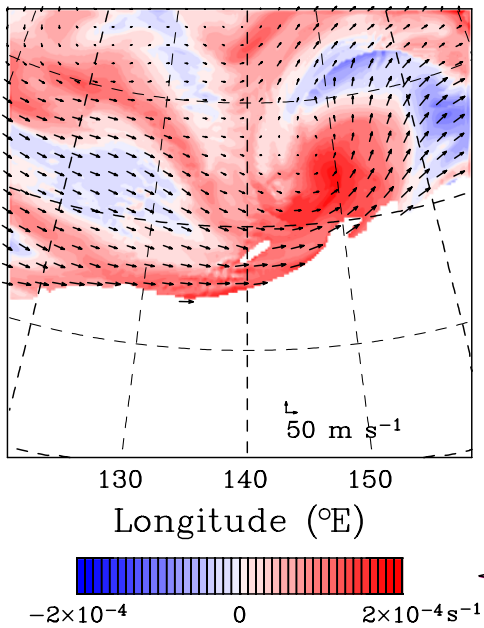

(c)

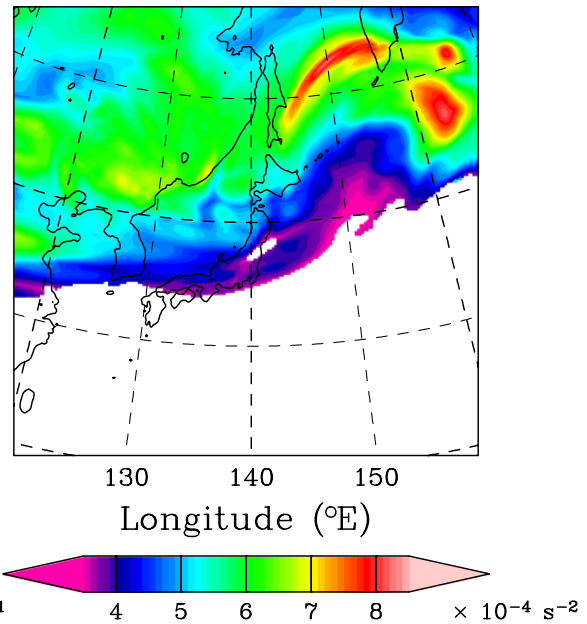

Figure 3 Tropopause height, wind speed at $300 \mathrm{hPa}, \zeta \mathrm{TP}$, horizontal winds at $Z_{\mathrm{TP}}$, and $N_{\max }^{2}$. (a) Height of the lowermost tropopause ( $Z_{\mathrm{TP}}$, color) and wind speed at $300 \mathrm{hPa}$ (contours, $\mathrm{m} \mathrm{s}^{-1}$ ), (b) $\zeta_{\mathrm{TP}}$ (color) and horizontal winds at $Z_{\mathrm{TP}}$ (arrows), and (c) $N_{\max }^{2}$ at $t=36 \mathrm{~h}$. (b) and (c) are only for the tropopause below $14 \mathrm{~km}$. 
will examine the relationship between these two quantities. In order to examine the dependence on $\zeta_{\mathrm{TP}}, 22,631$ temperature profiles within regions with $Z_{\mathrm{TP}}<14 \mathrm{~km}$ at $t=36 \mathrm{~h}$ are binned by $\zeta_{\mathrm{TP}}$ and averaged in each bin (Figure 4a). The bin width is $5 \times 10^{-5} \mathrm{~s}^{-1}$. The vertical coordinate is the height above the tropopause. The mean profiles for negative $\zeta_{\text {TP }}$ (dark blue lines) show clear temperature inversions with amplitudes of 4 to $5 \mathrm{~K}$ and thicknesses of 1.5 to $2 \mathrm{~km}$ just above the tropopause, whereas the profiles for positive $\zeta_{\mathrm{TP}}$ (red lines) do not show clear inversions. This result is consistent with previous observational and numerical studies (e.g., Randel et al. 2007; Son and Polvani 2007). Note that the absence of inversion layers in the mean temperature profile for $\zeta_{\text {TP }} \geq 1.5 \times 10^{-4} \mathrm{~s}^{-1}$ seems partly due to the vertical resolution of the model.

Figure $4 \mathrm{~b}$ is the same as Figure $4 \mathrm{a}$ but for the buoyancy frequency squared $\left(N^{2}\right)$. The tropospheric $N^{2}(4 \mathrm{~km}$ below the tropopause) is about $1.5 \times 10^{-4} \mathrm{~s}^{-2}$, whereas the stratospheric $N^{2}$ (4 km above the tropopause) is about 3 to $4 \times 10^{-4} \mathrm{~s}^{-2}$. The profiles for $\zeta_{\text {TP }}<0$ show a sharp local maximum just above the tropopause and a sharp local minimum just below the tropopause (except for $-5 \times 10^{-5} \leq \zeta_{\mathrm{TP}}<0 \mathrm{~s}^{-1}$ ), whereas the profiles for $\zeta_{\mathrm{TP}}>0$ show a smooth transition from the troposphere to the stratosphere without sharp peaks. As $\zeta \mathrm{TP}$ increases, the sharpness of the $N^{2}$ profiles decreases. Following Birner et al. (2006), the maximum $N^{2}$ within the temperature inversion (denoted by $N_{\max }^{2}$ ) is used as a measure of the strength of the TIL in the following analyses. In this study, $N_{\max }^{2}$ is searched for within $4 \mathrm{~km}$ above the local tropopause.
The horizontal map of $N_{\max }^{2}$ at $t=36 \mathrm{~h}$ is shown in Figure 3c. Regions with high $N_{\max }^{2}$ are located to the north of the surface cyclone, whereas regions with low $N_{\max }^{2}$ are located around the south edge of the analysis region. The distribution of $N_{\max }^{2}$ around the cyclone is similar to that in the idealized simulation with dry dynamics by Wirth and Szabo (2007) (their Figure three), implying common mechanisms between these two simulations. A comparison of Figure 3b,c shows that regions with high (low) $N_{\max }^{2}$ coincide with negative (positive) $\zeta_{\mathrm{TP}}$. Thus, in general, a negative correlation exists between $\zeta_{\text {TP }}$ and $N_{\max }^{2}$ in the horizontal distributions at $t=36 \mathrm{~h}$. However, the regions of $\zeta_{\mathrm{TP}}<0$ in the eastern part of the domain coincide with $N_{\max }^{2}$ greater than $8 \times 10^{-4} \mathrm{~s}^{-2}$ (red regions in Figure 3c), whereas those with similar negative values of $\zeta_{\mathrm{TP}}$ in the western part coincide with $N_{\max }^{2}$ less than $7 \times 10^{-4} \mathrm{~s}^{-2}$ (green and blue regions in Figure 3c), implying the existence of other factors that determine $N_{\max }^{2}$.

The relationship between $\zeta_{\mathrm{TP}}$ and $N_{\max }^{2}$ is further examined along the life cycle of the cyclone. Figure 5 shows two-dimensional histograms of $\zeta_{\text {TP }}$ (the horizontal axis) and $N_{\max }^{2}$ (the vertical axis) at 6-h intervals. From $t=0$ to $18 \mathrm{~h}$, the negative correlation between $\zeta_{\mathrm{TP}}$ and $N_{\max }^{2}$ is not clear. The correlation coefficient between $\zeta_{\mathrm{TP}}$ and $N_{\max }^{2}$ is -0.28 at $t=0 \mathrm{~h}$ and increases to -0.64 at $t=18 \mathrm{~h}$. At the initial time $(t=0)$, the TIL might be underestimated due to the coarser resolution of the NCEP FNL, which is used as the initial condition. However, it is difficult to distinguish the spin-up of the TIL from the evolution of the TIL due to the synoptic evolution. Thus, we mainly analyze $t=24$ to $36 \mathrm{~h}$. $(\times 1000 \mathrm{~m})^{(\mathrm{a})}$

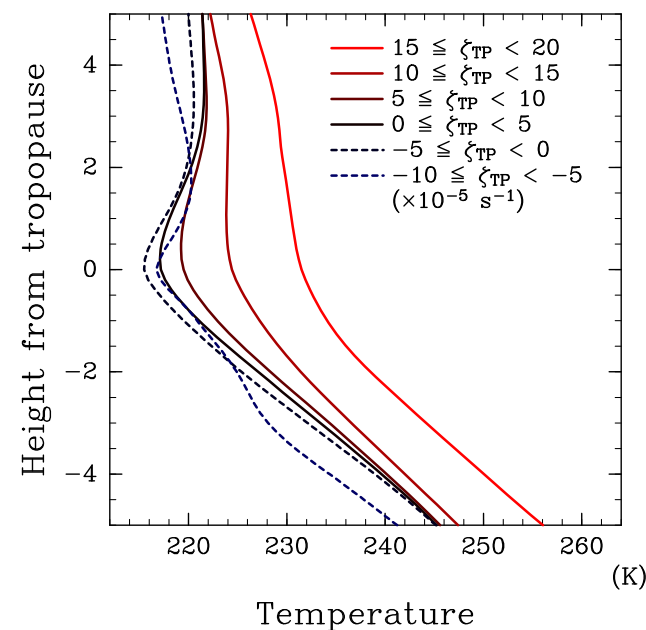

(b)

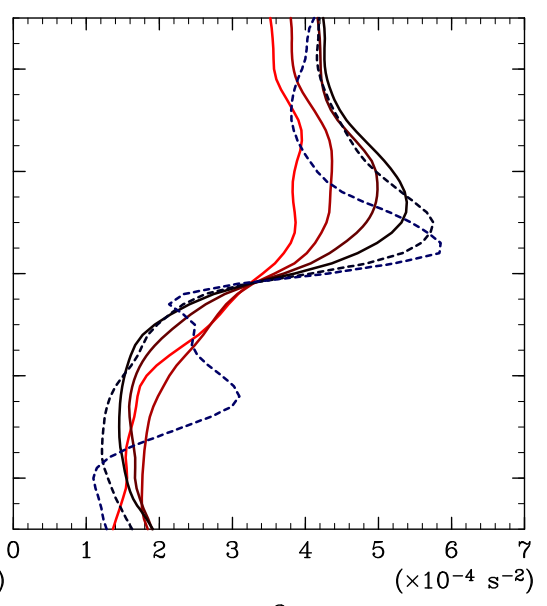

$\mathrm{N}^{2}$

Figure 4 Mean profiles of temperature and $N^{2}$ for each category of $\zeta_{\text {TP }}$. Mean profiles of (a) temperature and (b) $N^{2}$ for each category of $\zeta_{\text {TP }}$ at $t=36 \mathrm{~h}$ for the tropopause below $14 \mathrm{~km}$. Vertical axis is the height from the tropopause. 


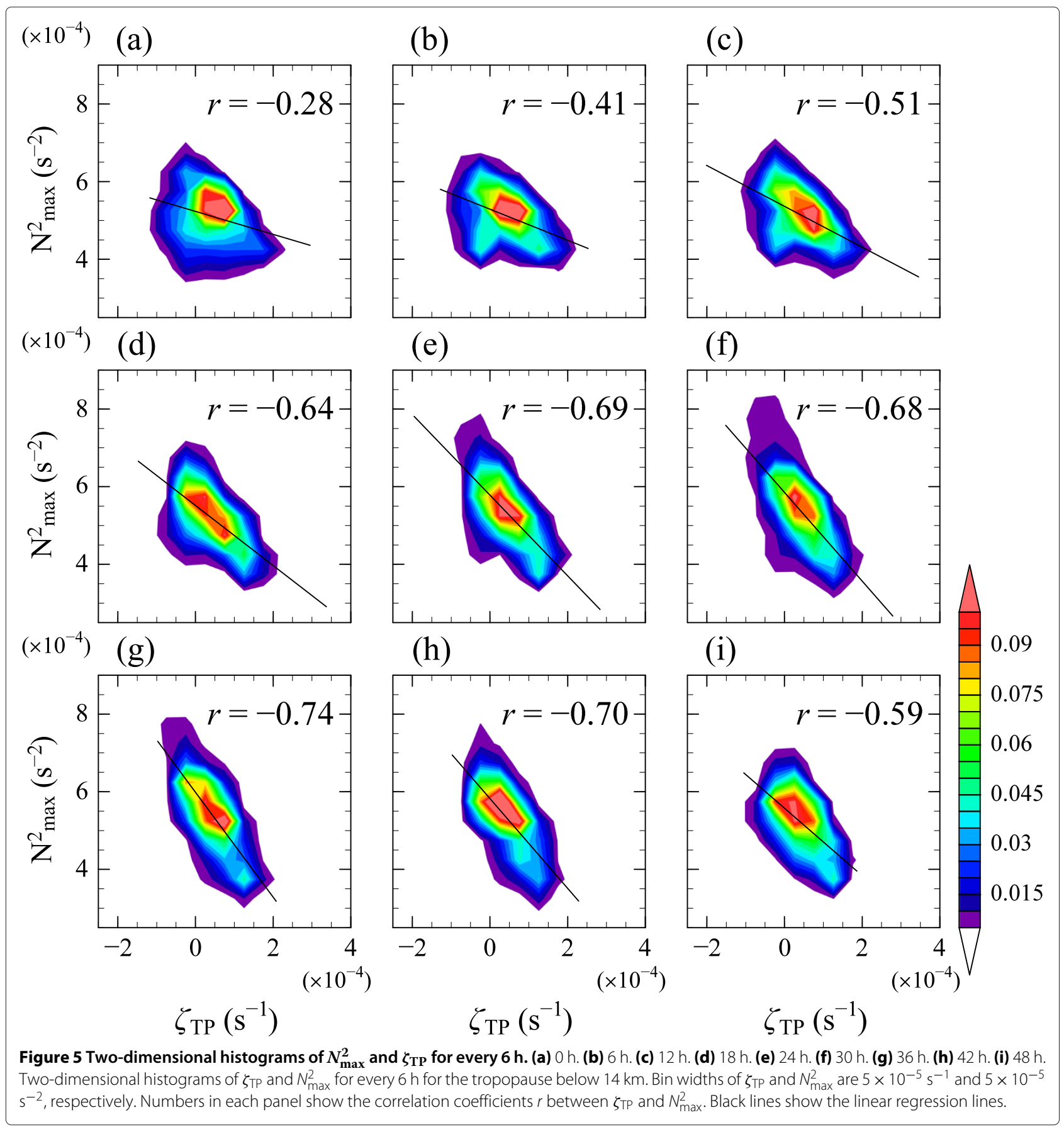

From $t=24$ to $42 \mathrm{~h}$, a clear negative correlation between $\zeta_{\text {TP }}$ and $N_{\max }^{2}$ is obtained with a correlation coefficient of about -0.7 . The linear regressions of $N_{\max }^{2}$ as functions of $\zeta_{\mathrm{TP}}$ (black lines in Figure 5) show steeper slopes, and the regressed values become about $7 \times 10^{-4} \mathrm{~s}^{-2}$ around $\zeta \mathrm{TP}=-1 \times 10^{-4} \mathrm{~s}^{-2}$, and about $5 \times 10^{-4} \mathrm{~s}^{-2}$ around $\zeta_{\mathrm{TP}}>2 \times 10^{-4} \mathrm{~s}^{-1}$. The proportionality coefficient between $\zeta_{\mathrm{TP}}$ and the mean $N_{\max }^{2}$ for $\zeta_{\mathrm{TP}}<0$ is about -1 , which is somewhat smaller than that for the reference run in Erler and Wirth
(2011), presumably due to the coarser spatial resolution of our model. The deviations from the regression lines are partly due to small-scalel disturbances such as gravity waves, which will be discussed in the following subsections.

From $t=42$ to $48 \mathrm{~h}$, the negative correlation between $\zeta_{\text {TP }}$ and $N_{\max }^{2}$ becomes weaker, and the correlation coefficient becomes about -0.6 at $t=48 \mathrm{~h}$. The linear regression slope becomes gentler. In summary, the negative correlation between $\zeta_{\mathrm{TP}}$ and $N_{\max }^{2}$ is clearer during the 
development and mature stages of the cyclone, whereas it is unclear before and after that period.

\section{Analysis of gravity waves around the tropopause}

Figure 6 shows $\partial w / \partial z$ at $260 \mathrm{hPa}$ every $3 \mathrm{~h}$ from $t=24$ to $36 \mathrm{~h}$. Red colors show vertical convergence, and blue colors show vertical divergence. An arc-shaped wave packet with east-west wave fronts over the Sea of OkhotskNorthwestern Pacific propagates northward. At $t=24$ $h$, the wave fronts extend eastward from the southern tip of Sakhalin. The wave fronts tilt gradually toward the southwest-northeast direction, and at $t=36 \mathrm{~h}$, they extend almost in a south-north direction off the east coast of middle Sakhalin. In the region of the arc-shaped wave

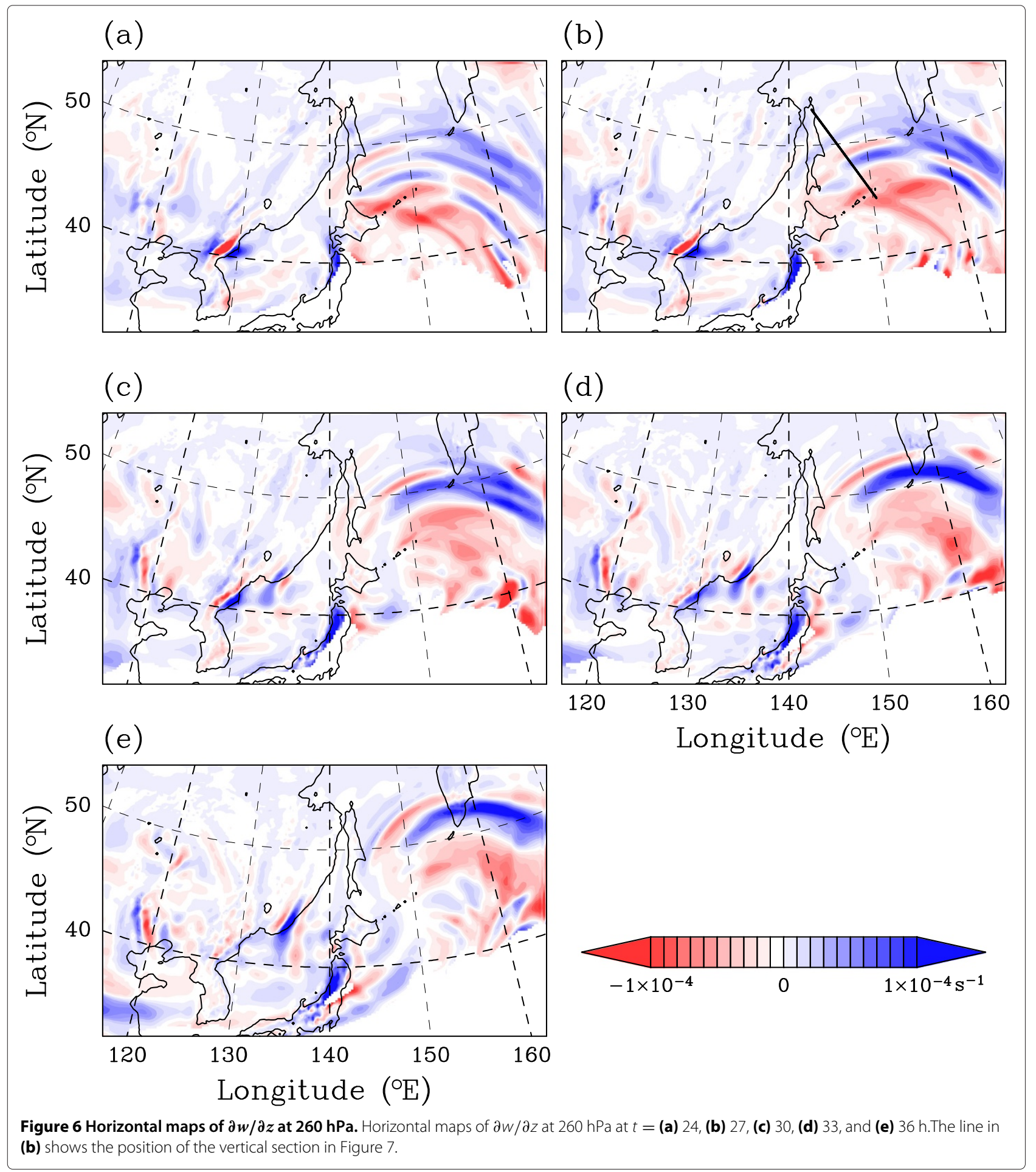


packet, $N_{\max }^{2}$ is the highest, where $\zeta_{\mathrm{TP}}$ is negative as shown in Figures $3 \mathrm{~b}, \mathrm{c}$ at the tropopause. The wave packets over the Asian continent around $\left(120^{\circ} \mathrm{E}, 40^{\circ} \mathrm{N}\right),\left(130^{\circ} \mathrm{E}, 40^{\circ} \mathrm{N}\right)$, and $\left(135^{\circ} \mathrm{E}, 45^{\circ} \mathrm{N}\right)$ are likely mountain waves. As the wind field changes with time, the mountain waves also change their structure.

The arc-shaped waves are robustly simulated in sensitivity experiments with different horizontal resolutions (15 and $20 \mathrm{~km}$ ), vertical resolutions (50 layers and 210 layers), numerical integration time steps (10 and $20 \mathrm{~s}$ ), time constants for nonlinear numerical diffusion $(1,200$ and 2,400 $\mathrm{s})$, or time constants for linear numerical diffusion $(600$ and 2,400 s). If the number of vertical layers is reduced to 50, the amplitude of the arc-shaped waves in $\partial w / \partial z$ becomes slightly weaker, and the associated peak in $N_{\max }^{2}$ also becomes smaller (not shown). The resolution dependency of the peak $N_{\max }^{2}$ is consistent with the results of the idealized experiment by Müller and Wirth (2009). On the other hand, the weakening of the TIL around the center of the cyclone also becomes gentle. Although the smallscale structures are different, the time evolution of the arc-shaped waves and the negative correlation between $\zeta$ TP and $N_{\max }^{2}$ does not change much.

Here, temporal modulation of local $N^{2}$ by propagating gravity waves or stationary disturbances is discussed in a simple manner because the regions of clear gravity waves coincide with the regions of large $N_{\max }^{2}$ (Figures $3 \mathrm{c}$ and 6e). If we use standard notations (e.g., Andrews et al. 1987),

$$
\begin{aligned}
\frac{\partial N^{2}}{\partial t} & \equiv \frac{\partial}{\partial t}\left(\frac{g}{\theta} \frac{\partial \theta}{\partial z}\right) \\
& =\frac{g}{\theta}\left(\frac{\partial}{\partial z}-\frac{1}{\theta} \frac{\partial \theta}{\partial z}\right)\left(\frac{\partial \theta}{\partial t}\right),
\end{aligned}
$$

where $g$ is the gravitational acceleration. If the process is adiabatic,

$$
\begin{aligned}
\frac{\partial N^{2}}{\partial t} & =\frac{g}{\theta}\left(\frac{\partial}{\partial z}-\frac{1}{\theta} \frac{\partial \theta}{\partial z}\right)(-\boldsymbol{u} \cdot \nabla \theta) \\
& =\frac{g}{\theta}\left(-\frac{\partial \boldsymbol{u}}{\partial z} \cdot \nabla \theta-\boldsymbol{u} \cdot \nabla \frac{\partial \theta}{\partial z}+\frac{1}{\theta} \frac{\partial \theta}{\partial z} \boldsymbol{u} \cdot \nabla \theta\right),
\end{aligned}
$$

where $\boldsymbol{u} \equiv(u, v, w)$ denotes three-dimensional winds. If $\theta$ is assumed to be uniform in the horizontal direction,

$$
\frac{\partial N^{2}}{\partial t} \approx \frac{g}{\theta}\left[-\frac{\partial w}{\partial z} \frac{\partial \theta}{\partial z}+w\left\{\frac{1}{\theta}\left(\frac{\partial \theta}{\partial z}\right)^{2}-\frac{\partial^{2} \theta}{\partial z^{2}}\right\}\right] .
$$

\section{Vertically propagating disturbances}

If $w=A \sin (m z-\omega t)$,

$$
\begin{aligned}
\frac{\partial N^{2}}{\partial t}=A & \frac{g}{\theta}\left[-m \cos (m z-\omega t) \frac{\partial \theta}{\partial z}\right. \\
& \left.+\sin (m z-\omega t)\left\{\frac{1}{\theta}\left(\frac{\partial \theta}{\partial z}\right)^{2}-\frac{\partial^{2} \theta}{\partial z^{2}}\right\}\right],
\end{aligned}
$$

where $A$ is a constant, $m$ is the vertical wave number, and $\omega$ is the frequency. Assuming that $\partial \theta / \partial z$ is a positive constant and $\partial \theta / \partial z \ll m \theta$,

$$
\frac{\partial N^{2}}{\partial t} \approx-A m N^{2} \cos (m z-\omega t) .
$$

This gives

$$
\begin{aligned}
N^{2} & =\int \frac{\partial N^{2}}{\partial t} d t \\
& \approx \frac{A m N^{2}}{\omega} \sin (m z-\omega t)+\text { const, } \\
\frac{\partial w}{\partial z} & =A m \cos (m z-\omega t), \\
\frac{\partial^{2} w}{\partial z^{2}} & =-A m^{2} \sin (m z-\omega t) .
\end{aligned}
$$

If the phase propagation is downward $(m / \omega<0), N^{2}$ and $\partial^{2} w / \partial z^{2}$ become in phase. For simplicity, the feedback from the changes in $N^{2}$ to the dispersion relation of the wave is considered to be free from the variation in $N^{2}$ in this paper. Nonlinearity in the TIL (e.g., Miyazaki et al. 2010a) is beyond the scope of this paper, which focuses on a diagnosis of linear wave propagation.

\section{Stationary disturbances}

If $w=A \sin (m z)$ and the same assumption is made with regard to $\theta$ and $N^{2}$ as above, from Equation 3,

$$
\begin{aligned}
& N^{2} \approx-A m N^{2} \cos (m z) \cdot t+\text { const }, \\
& \frac{\partial w}{\partial z}=A m \cos (m z) .
\end{aligned}
$$

In this case, $-\partial w / \partial z$ and $N^{2}$ are in phase.

Figure 7 shows the vertical cross section of $\partial w / \partial z$ (color) and $N^{2}$ (contour) along the line shown in Figure 6b

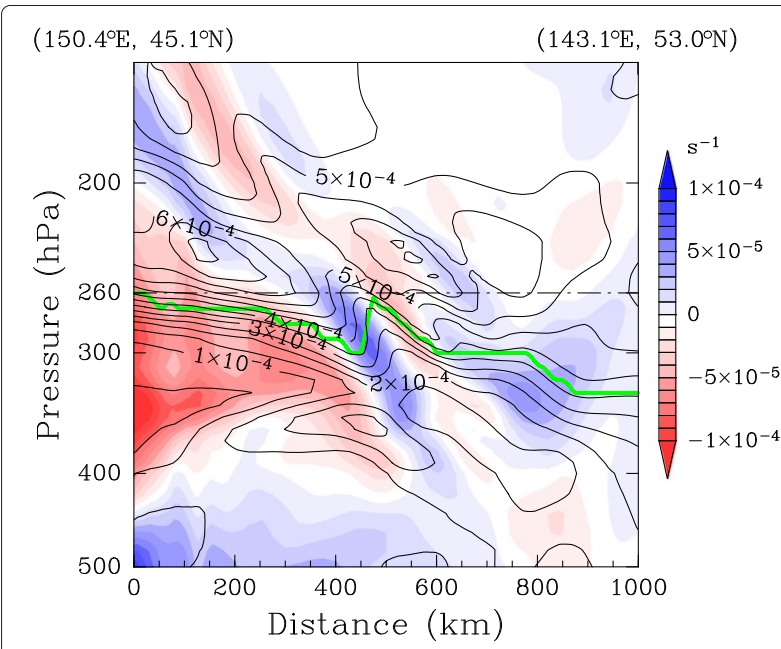

Figure 7 Vertical cross sections of $\partial \boldsymbol{w} / \partial z$ and $N^{2}$. Vertical cross sections of $\partial W / \partial z$ (color, $\mathrm{s}^{-1}$ ) and $N^{2}$ (contour, $\mathrm{s}^{-2}$ ) at $t=27 \mathrm{~h}$ along the line shown in Figure 6b. Tropopause is denoted by the green line. The dashed-dotted line shows the $260 \mathrm{hPa}$ level. 
at $t=27 \mathrm{~h}$. The color coding is the same as that in Figure 6. The green line shows the tropopause. A wave pattern is located at around 0 to $800 \mathrm{~km}$ in the horizontal direction and 300 to $200 \mathrm{hPa}$ in the vertical direction, which corresponds to the arc-shaped wave packet in Figure 6.

The dispersion relation of the wave packet around the tropopause at $147^{\circ} \mathrm{E}, 49^{\circ} \mathrm{N}, t=27 \mathrm{~h}$ is examined because the wave packet is clearer at this point and time. The region has a strong wind shear and a gap in $N^{2}$, showing a nonlinear nature at a later time. From Figures $6 \mathrm{~b}$ and 7 , the wavelengths in the $x, y$, and $z$ directions are $5.0 \times 10^{2} \mathrm{~km}$, $1.8 \times 10^{2} \mathrm{~km}$, and $2.0-3.0 \mathrm{~km}$, respectively. From Figure 7 , $N^{2}$ is about $5 \times 10^{-4} \mathrm{~s}^{-2}$. Using the Coriolis parameter at $50^{\circ} \mathrm{N}, f=1.1 \times 10^{-4} \mathrm{~s}^{-1}$, the dispersion relation for an inertia-gravity wave (e.g., Gill 1982),

$$
\hat{\omega}=\omega-\boldsymbol{k} \cdot \boldsymbol{u}=\sqrt{\frac{N^{2}\left(k^{2}+l^{2}\right)+f^{2} m^{2}}{k^{2}+l^{2}+m^{2}}},
$$

gives an intrinsic frequency $\hat{\omega}=2.9-4.1 \times 10^{-4} \mathrm{~s}^{-1}$, or a period of about $2.5-3.7 \times 10^{2}$ minutes. Here, $\omega$ denotes the frequency in a fixed frame of reference, $k$ and $l$ are the wavenumbers along the $x$ and $y$ directions, respectively, and $\boldsymbol{k} \equiv(k, l, m)$. We assume $k>0, l<0$, and $m<0$ from the phase lines in Figures 6 and 7. Substituting environmental wind speeds of of about $(2.8 \times 10,3.2 \times 10$, $\left.1.8 \times 10^{-2}\right) \mathrm{m} \mathrm{s}^{-1}, \omega$ becomes -5.4 to $-4.0 \times 10^{-4} \mathrm{~s}^{-1}$ or a period of about 1.9 to $2.6 \times 10^{2} \mathrm{~min}$. In the model, the period at a fixed point is about $2.0 \times 10^{2}$ min with northward phase propagation, or $\omega=-5.2 \times 10^{-3} \mathrm{~s}^{-1}$, which is close to the value estimated from Equation 11. Thus, this wave satisfies the dispersion relation for an inertia-gravity wave.

From a hodograph analysis of high-pass filtered horizontal winds, it is also confirmed that the wave is an inertia-gravity wave that has a downward phase speed (not shown). Although detailed analysis of gravity waves is beyond the scope of this paper, several discussions will be presented later.

\section{Relationship between TIL and gravity waves}

In this subsection, the relationship between the TIL and the gravity waves is further examined to ascertain if the vertical convergence shown in Figure 7 is the dominant factor in the strengthening of the TIL during the development and mature stages of the cyclone.

In Figure 7, $\partial w / \partial z$ is in quadrature with $N^{2}$ in the stratosphere; the local maxima of $N^{2}$ are located between the local maxima of $\partial w / \partial z$ above and the local minima below. From Equations 6 to 7, this implies that the wave pattern for $N^{2}$ is produced by the downward propagating wave disturbance of $w$, which is consistent with the analysis in the previous subsection that indicated that the wave with a downward phase speed is an inertia-gravity wave. These high- $N^{2}$ regions are detected as TILs.

It is important to confirm that the amplitudes of the wave patterns in $N^{2}$ and $w$ are consistent with each other. From Equation 6, the amplitude of $N^{2}$ becomes $A m N^{2} / \omega$. In Figure 7, the amplitude of $\partial w / \partial z$, which becomes $A m$, is about $5 \times 10^{-5} \mathrm{~s}^{-1}$. Substituting $A m=5 \times 10^{-5} \mathrm{~s}^{-1}$, $N^{2}=5 \times 10^{-4} \mathrm{~s}^{-2}$, and $\omega=3.1 \times 10^{-4} \mathrm{~s}^{-1}$ into Equation 6 , the amplitude of the wave pattern of $N^{2}$ is estimated to be $8.3 \times 10^{-5} \mathrm{~s}^{-2}$, whereas the actual amplitude in Figure 7 is about $10^{-4} \mathrm{~s}^{-2}$. These are the same order of magnitude as each other. As the amplitude of the wave pattern for $N^{2}$ is proportional to $N^{2}$, the wave pattern is clearly seen only within the TIL (Figure 7).

Figure 8 shows histograms of $N_{\max }^{2}$ in the TIL, using the hourly outputs from $t=24$ to $36 \mathrm{~h}$. Horizontal grid points within the analysis regions of 13 snapshots (in total 286,836 grid points) are categorized by the sign of either (a) $\zeta_{\text {TP }}$, (b) $\partial w / \partial z$, or (c) $\partial^{2} w / \partial z^{2}$. The histograms of $N_{\max }^{2}$ are created for each group. The bin width of the histograms is $5 \times 10^{-5} \mathrm{~s}^{-1}$. Each histogram is normalized by its sample size.

First, differences due to the sign of $\zeta_{\text {TP }}$ are examined (Figure 8a). The peak for $\zeta_{\mathrm{TP}}<0$ appears at $N_{\max }^{2}=$ $5.25 \times 10^{-4} \mathrm{~s}^{-2}$, whereas that for $\zeta_{\mathrm{TP}} \geq 0$ appears at $N_{\max }^{2}=6.25 \times 10^{-4} \mathrm{~s}^{-2}$. This result is consistent with the negative correlation between $\zeta_{\mathrm{TP}}$ and $N_{\max }^{2}$ in Figures 4 to 5 .

Next, differences due to the sign of $\partial w / \partial z$ are examined in Figure $8 \mathrm{~b}$. Although the two histograms both peak at $N_{\max }^{2}=5.25 \times 10^{-4} \mathrm{~s}^{-2}$, the distribution for $\partial w / \partial z<0$ $\mathrm{s}^{-1}$ (short-dashed) appears slightly to the right of that for $\partial w / \partial z \geq 0 \mathrm{~s}^{-1}$ (solid), indicating that $N_{\max }^{2}$ increases as $\partial w / \partial z$ decreases. This indicates that stationary disturbances enhance the TIL through vertical convergence. The difference between positive and negative $\partial w / \partial z$ is slightly clearer when the histograms are computed only for the regions of $\zeta_{\mathrm{TP}}<0$ (Figure 9). For $\zeta_{\mathrm{TP}}<0$, the peak for $\partial w / \partial z \geq 0$ is at $N_{\max }^{2}=5.75 \times 10^{-4} \mathrm{~s}^{-2}$, and that for $\partial w / \partial z<0$ is at $N_{\max }^{2}=6.25 \times 10^{-4} \mathrm{~s}^{-2}$ (Figure 9a). For $\zeta_{\mathrm{TP}} \geq 0$, the two histograms peak at the same $N_{\max }^{2}$ (Figure 9b). Note that the time integration of $\partial w / \partial z$ strengthens $N^{2}$ when the stationary disturbances are dominant. Thus, local $\partial w / \partial z$ at a specific location and time may have little correlation with $N_{\max }^{2}$.

Finally, differences due to the sign of $\partial^{2} w / \partial z^{2}$ are examined in Figure 8c. The two histograms both peak at $N_{\max }^{2}=5.25 \times 10^{-4} \mathrm{~s}^{-2}$. However, the distribution for $\partial^{2} w / \partial z^{2} \geq 0$ is located to the right of that for $\partial^{2} w / \partial z^{2}<$ 0 , indicating that $N_{\max }^{2}$ increases as $\partial^{2} w / \partial z^{2}$ increases. This implies that waves with a downward phase propagation are important for the strengthening of the TIL. The difference between positive and negative $\partial^{2} w / \partial z^{2}$ is clearer when the histograms are computed only for the 


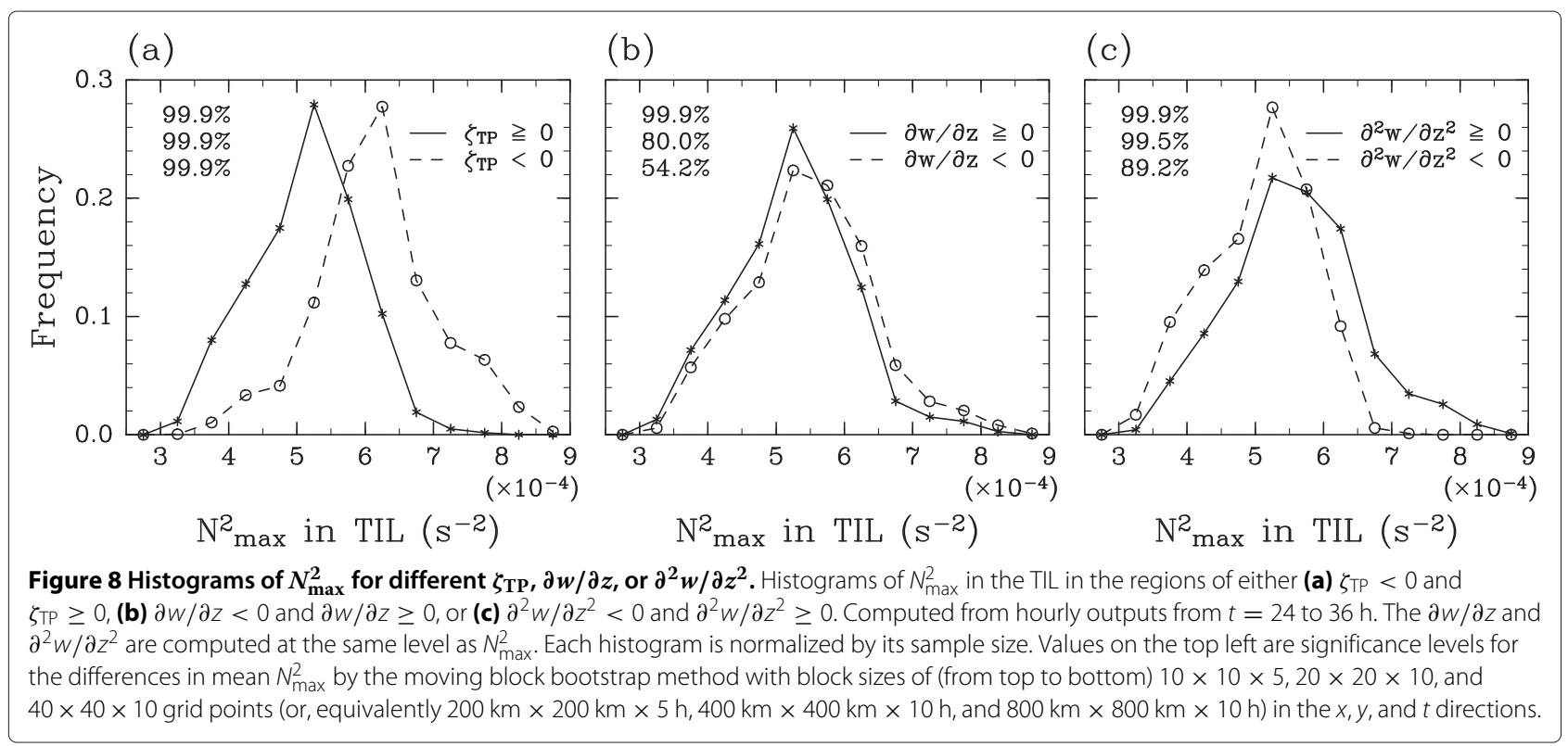

regions of $\zeta_{\mathrm{TP}}<0$ (Figure 10). For $\zeta_{\mathrm{TP}}<0$, the peak for $\partial^{2} w / \partial z^{2}<0$ is at $N_{\max }^{2}=5.75 \times 10^{-4} \mathrm{~s}^{-2}$ and that for $\partial^{2} w / \partial z^{2} \geq 0$ is at $N_{\max }^{2}=6.25 \times 10^{-4} \mathrm{~s}^{-2}$ (Figure 10a). For $\zeta_{\mathrm{TP}} \geq 0$, the two histograms peak at the same $N_{\max }^{2}$ (Figure 10b). The difference by $\partial^{2} w / \partial z^{2}$ in Figure 10a is clearer than that by $\partial w / \partial z$ in Figure 9a. Although waves with upward phase propagation may also exist, their contribution seems to be smaller.

It is not a straightforward task to test the statistical significance of spatially correlated samples with appropriate estimates of correlation scales. Thus, we have adopted the moving block bootstrap method (Künsch 1989) to test the statistical significance of the differences in mean $N_{\text {max }}^{2}$. Because the optimum block size is unknown, we choose block sizes of $10 \times 10 \times 5,20 \times 20 \times 10$, and $40 \times 40 \times 10$ grid points (or, equivalently $200 \mathrm{~km} \times 200 \mathrm{~km} \times 5 \mathrm{~h}, 400$ $\mathrm{km} \times 400 \mathrm{~km} \times 10 \mathrm{~h}$, and $800 \mathrm{~km} \times 800 \mathrm{~km} \times 10 \mathrm{~h}$ ) in the $x, y$, and $t$ directions. We obtained 10,000 bootstrap observations each. As a result, the differences in the means in Figure 8a,c are significant to levels higher than 99\% except for Figure $8 \mathrm{c}$ with the largest block size (see the values at the top left of each figure). The difference in the means in Figure $8 \mathrm{~b}$ is not as significant as that in other pairs of data except the smallest block size. Statistical tests for Figures 9

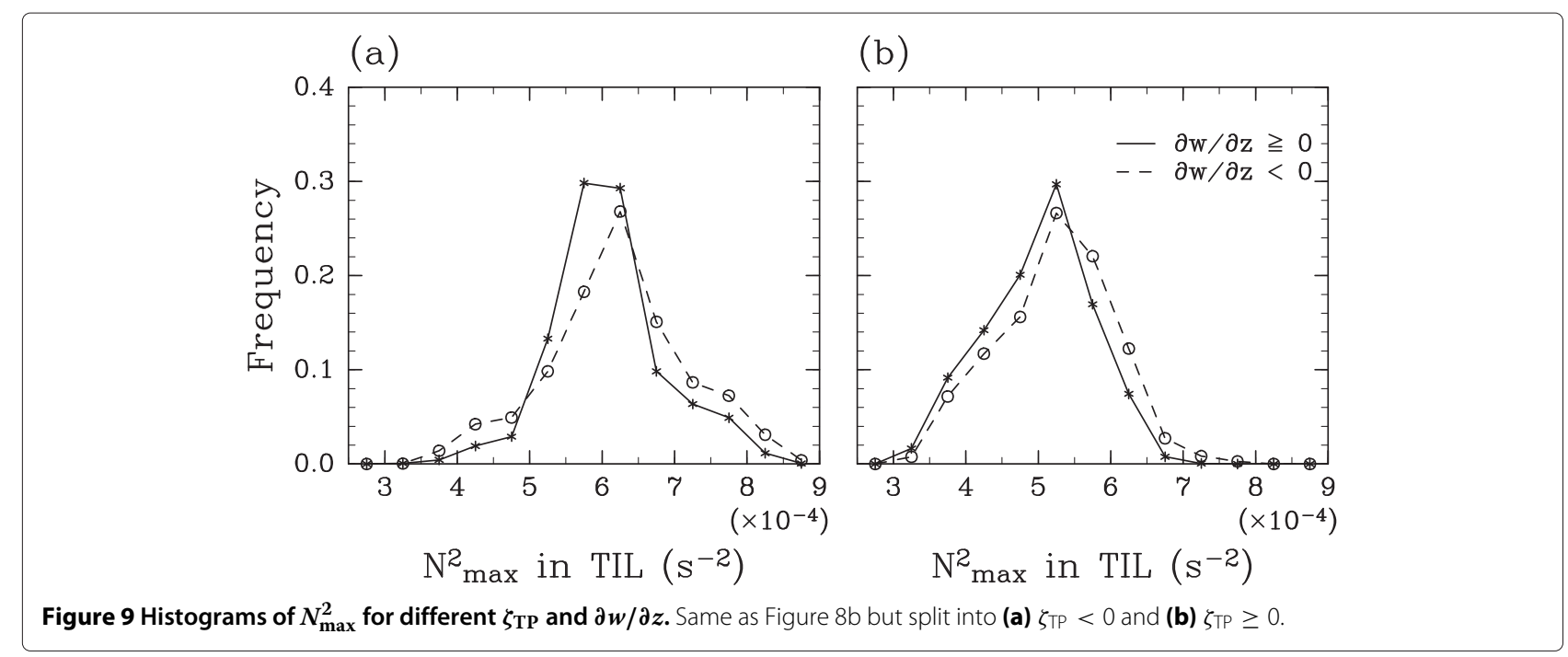


(a)

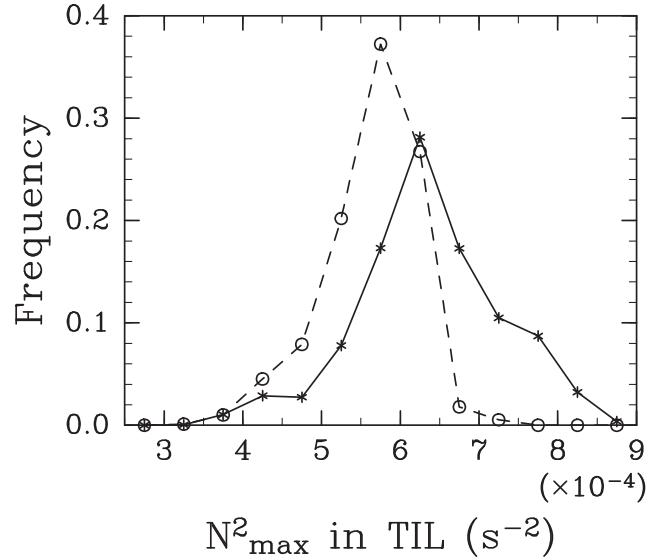

(b)

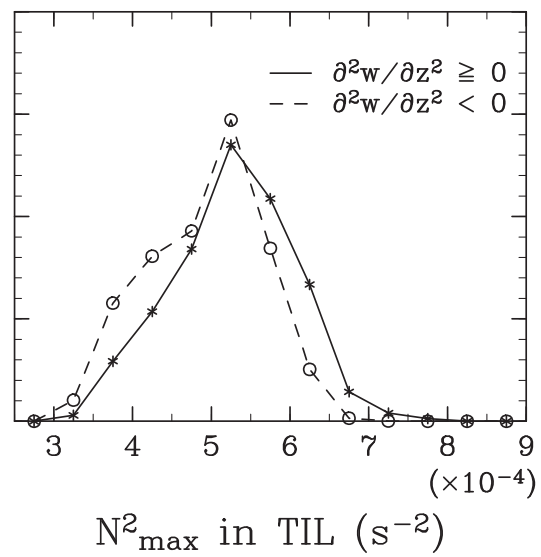

Figure 10 Histograms of $N_{\max }^{2}$ for different $\zeta_{T P}$ and $\partial^{2} w / \partial z^{2}$. Same as Figure 8c but split into (a) $\zeta_{T P}<0$ and (b) $\zeta_{T P} \geq 0$.

and 10 are more difficult to construct, and will not be shown in this paper.

\section{Discussion}

In our experiment, the TIL is formed as the cyclone develops. During the development and mature stages of the cyclone, the negative correlation between $\zeta_{\mathrm{TP}}$ and $N_{\max }^{2}$ becomes clearer (Figure 5). In particular, $N_{\max }^{2}$ for negative $\zeta_{\text {TP }}$ increases, whereas $N_{\max }^{2}$ for positive $\zeta_{\text {TP }}$ decreases. This is consistent with the results of idealized simulations by Wirth and Szabo (2007) and Erler and Wirth (2011), in which the TIL becomes sharper as baroclinically unstable disturbances develop, and the TIL decays as the cyclone decays. Our experiment confirms that the TIL shows a similar time evolution in a realistic life cycle of an extratropical cyclone.

From Equations 6 to 10, it is expected that a steady disturbance of $\partial w / \partial z$ produces a pattern of $N^{2}$ that is in phase with $-\partial w / \partial z$, whereas a downward-propagating wave produces a pattern of $N^{2}$ that is in phase with $\partial^{2} w / \partial z^{2}$. As shown in Figure $8, N_{\max }^{2}$ has a negative correlation with $\partial w / \partial z$, whereas $N_{\max }^{2}$ has a positive correlation with $\partial^{2} w / \partial z^{2}$. From these two facts, it is concluded that the TIL in our model result is strongly controlled by the dynamical processes. In particular, inertia-gravity waves, which have not been investigated in depth in previous studies on the TIL, play a significant role. Note that the western half of the analysis region is dominated by nearly stationary patterns of $\partial w / \partial z$ by the synoptic disturbances and the mountain waves, whereas the eastern half is dominated by the effect of vertically propagating gravity waves. Although both the western and eastern sides contribute to the negative correlation between $\zeta_{\text {TP }}$ and $N_{\max }^{2}$, the eastern side exhibits both the highest and the lowest
$N_{\max }^{2}$ values. The lowest $N_{\max }^{2}$ appears around the center of the cyclone and the highest $N_{\max }^{2}$ is produced by the arc-shaped wave packet. This fact also implies that the development of the cyclone and the radiation of the gravity waves are important for the development of the negative correlation.

Radiation of inertia-gravity waves from synoptic systems has been investigated by several groups using numerical experiments (e.g., O'Sullivan and Dunkerton 1995; Plougonven and Snyder 2007; Zhang 2004; Zülicke and Peters 2006). For example, Plougonven and Snyder (2007) simulated two types of wave packets generated around the tropopause region in a so-called LC2-type baroclinic life cycle experiment. The arc-shaped packet of the inertiagravity waves shown in Figure 6 is similar to that in previous studies and can be considered a representative feature associated with developing baroclinic disturbances. Under the assumption that gravity waves of this type are ubiquitous around synoptic systems in the extratropics, the enhancement of the TIL by gravity waves may have an impact on the climatology of the TIL. Furthermore, gravity waves generated at the exit region of jet streaks tend to experience 'wave capture' (e.g., McIntyre 2009), staying within the same region relative to the synoptic disturbances. Thus, these gravity waves may not be just linear and transient features, but could be more persistent forcings to the tropopause region through nonlinear interactions. This may be the reason the negative correlation between $\zeta_{\mathrm{TP}}$ and $N_{\max }^{2}$ is clearer during the development and mature stages of the cyclone. Thus, this relationship among gravity waves, $\zeta_{\mathrm{TP}}$, and $N_{\max }^{2}$ could be a general feature associated with extratropical cyclones. Proving the statistical significance of the effect of gravity waves radiated from synoptic disturbances is a subject 
we plan to investigate in the future using a regional atmospheric model.

The model-simulated TILs are validated using 136 operational radiosonde profiles (distributed by the University of Wyoming) at 42 stations in the computational domain, except for those within 20 grid points from the lateral boundaries. Figure 11a shows the stations used in the analysis. Temperature profiles are resampled every $10 \mathrm{~m}$ in the vertical direction, and running means over 101 points are taken to smooth the profiles so that they can be compared with those in the model. The cut-off scale is about $2 \mathrm{~km}$ (about ten times greater than the vertical grid spacing of the model around the tropopause) to take into account the effective resolution of the model (e.g., Skamarock 2004) and small-scale gravity waves that are not resolvable in the model. Figure 11b shows the smoothed temperature profiles at 1200 UTC 20 February, 2009 at the ten stations denoted by filled circles in Figure 11a. Tropopauses are denoted by markers. The lowest tropopause is located between 300 and $500 \mathrm{hPa}$, except for the two profiles in the south. This is consistent with the tropopause height in the model (Figure 2). Although temperature inversions with much smaller depths than the smoothing scale disappear, temperature inversions just above the local tropopauses are discernible. In particular, the second and third profiles from the right (north) show clear TILs.

In total, 99 temperature profiles having local tropopauses below $14 \mathrm{~km}$ are selected at 35 stations from 0000
UTC 20 to 0000 UTC 21 February, 2009, and $N_{\max }^{2}$ is computed for each profile. Figure 11c shows the scatter diagram between the observed (the horizontal axis) and model (the vertical axis) $N_{\max }^{2}$ at the same time and place. The model values are linearly interpolated to the corresponding observation sites. The correlation coefficient between the observed and simulated $N_{\max }^{2}$ is 0.59 . The mean $N_{\max }^{2}$ in the model is $5.3 \times 10^{-4} \mathrm{~s}^{-2}$, whereas that in the observation is $5.9 \times 10^{-4} \mathrm{~s}^{-2}$, indicating that the model underestimates the strength of the TILs. Overall, it is concluded that the model reproduced the observed $N_{\max }^{2}$ reasonably well.

In summary, the difference between our results and previous studies is that the effect of gravity waves has been explicitly taken into account in our analyses. As synoptic disturbances develop, gravity wave activities also increase in a specific region relative to the synoptic systems. The inertia-gravity waves are robustly reproduced with a range of model resolutions and parameters. Both synoptic-scale wave breaking and gravity wave activity seem to contribute to the time evolution of $N_{\max }^{2}$. Although we have presented a single case study on TIL formation associated with extratropical explosive cyclogenesis, it is well known that explosive cyclogenesis occurs frequently in the mid-latitude storm tracks from autumn to spring (e.g., Sanders and Gyakum 1980). Furthermore, our result is consistent with the fact that the dynamical TIL formation is considered to be dominant in winter mid-latitudes (e.g., Birner 2010; Miyazaki et al. 2010b; Randel and Wu 2010).

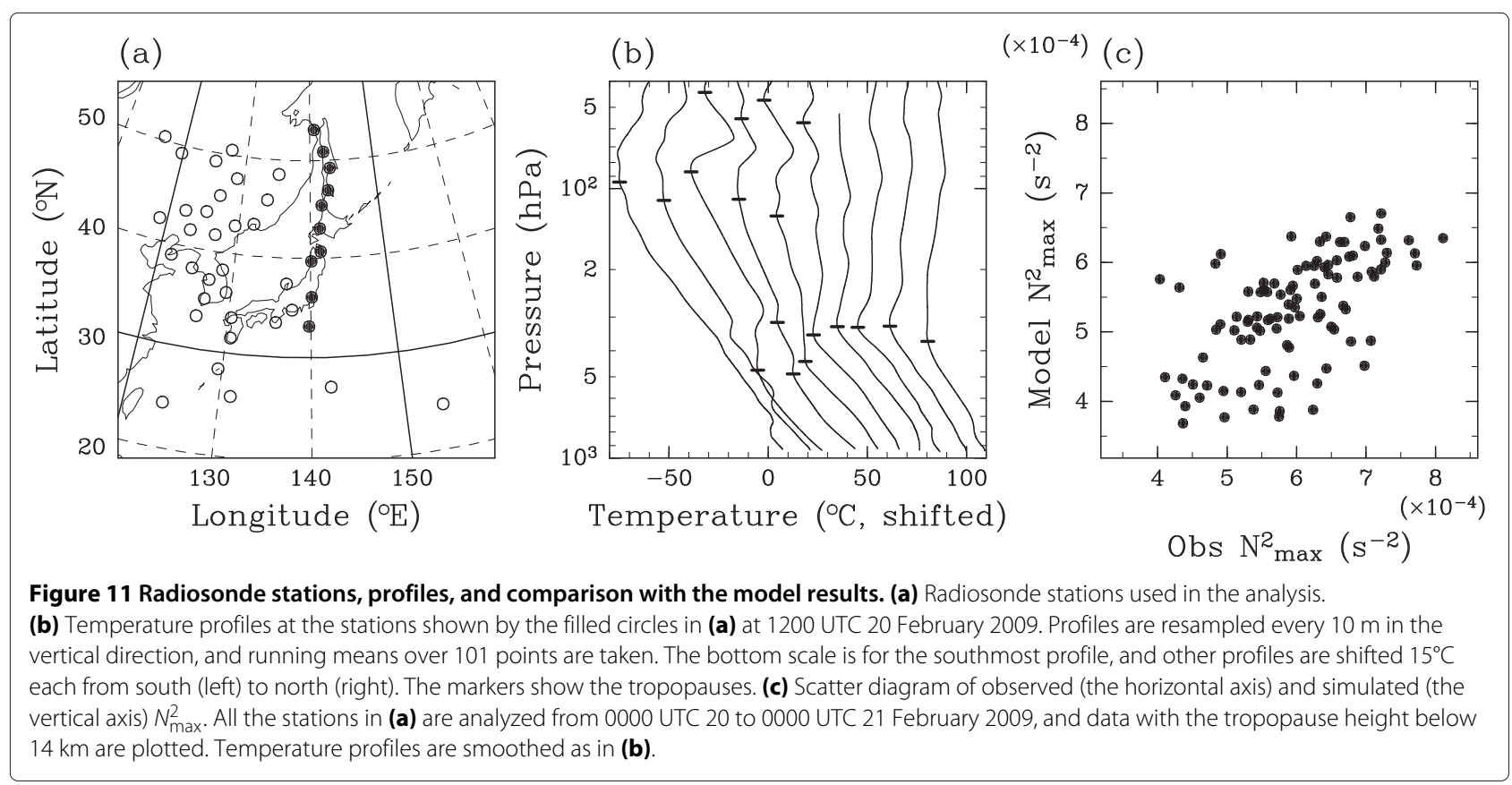




\section{Conclusions}

We conducted a numerical experiment using a regional atmospheric model with realistic configurations to investigate the formation of the extratropical TIL associated with a realistic synoptic disturbance in mid-latitudes. The model successfully reproduced the TIL associated with an explosive cyclogenesis that occurred from 19 to 21 February, 2009 over Japan. The model also reproduced the negative correlation between the strength of the TIL (measured by the maximum buoyancy frequency squared in the TIL, $N_{\max }^{2}$ ) and the relative vorticity near the tropopause $\left(\zeta_{\mathrm{TP}}\right)$, which has been reported by observations (e.g., Randel et al. 2007) and previous model studies (e.g., Son and Polvani 2007). However, the negative correlation was clear only during the development and mature stages of the cyclogenesis. This suggests that the evolution of the cyclone plays an important role in the formation of the TIL.

To ascertain the dynamical formation of the TIL including the effects of gravity waves, the relationship between $N_{\max }^{2}$ and the vertical divergence, $\partial w / \partial z$, and its vertical derivative, $\partial^{2} w / \partial z^{2}$, were analyzed. Histograms of $N_{\max }^{2}$ showed that regions of vertical convergence $(\partial w / \partial z<$ 0 ) correspond to higher $N_{\max }^{2}$ as well as regions of $\partial^{2} w / \partial z^{2}>0$ (Figure 8). The former indicated the effect of the dynamical formation by large- to synopticscale motions (e.g., Wirth 2003; Birner 2010), whereas the latter indicated the effect of small-scale waves with downward phase propagation. This tendency was clearer in the regions of negative relative vorticities at the tropopause.

By taking account of the fact that the gravity wave activity associated with the cyclone and the jet streak seem to be enhanced during the development and mature stages of the cyclone, the vertical convergence by gravity waves associated with synoptic weather systems could be a key element in the formation of the negative correlation between the strength of the TIL and the local relative vorticity at the tropopause.

\section{Competing interests}

The authors declare that they have no competing interests.

\section{Authors' contributions}

SO conducted the numerical experiment, analyses, manipulation of graphics, and dynamical interpretation. MT conducted the analyses and interpretation. SY proposed the framework of the study and contributed to the analyses and interpretation. All authors read and approved the final manuscript.

\section{Acknowledgements}

The authors thank the two anonymous reviewers for their helpful comments. This work was supported by JSPS KAKENHI (S) Grant Number 24224911 and Kyoto University's Global COE Program 'Sustainability/Survivability Science for a Resilient Society Adaptable to Extreme Weather Conditions' for FY 2009-13. The figures were produced by the GFD-DENNOU Library.

\section{Author details}

${ }^{1}$ RIKEN Advanced Institute for Computational Science, 7-1-26

Minatojima-minami-machi, Chuo-ku, 650-0047 Kobe, Japan. ${ }^{2}$ Weather Caster Network, 1-14-21 Ueno-Sakuragi, Taito-ku, 110-0002 Tokyo, Japan. ${ }^{3}$ Graduate
School of Science, Kyoto University, Kitashirakawa-Oiwake-cho, Sakyo-ku, 606-8502 Kyoto, Japan.

Received: 7 April 2014 Accepted: 23 August 2014

Published online: 30 September 2014

\section{References}

Andrews DG, Holton JR, Leovy CB (1987) Middle Atmosphere Dynamics. Academic Press, San Diego, p 489

Birner T, Dörnbrack A, Schumann U (2002) How sharp is the tropopause at midlatitudes?. Geophys Res Lett 29:1700. doi:10.1029/2002GL015142

Birner T, Sankey D, Shepherd TG (2006) The tropopause inversion layer in models and analyses. Geophys Res Lett 33:14804. doi:10.1029/2006GL026549

Birner T (2010) Residual circulation and tropopause structure. J Atmos Sci 67:2582-2600

Erler AR, Wirth V (2011) The static stability of the tropopause region in adiabatic baroclinic life cycle experiments. J Atmos Sci 68:1178-193

Gill AE (1982) Atmosphere-Ocean Dynamics. Academic Press, London, p 662

Japan Meteorological Agency (2009) Daily weather charts No. 85 February 2009. Tenki 56:242-243. (in Japanese)

Künsch HR (1989) The jackknife and the bootstrap for general stationary observations. Ann Statist 17:1217-1241

Müller A, Wirth V (2009) Resolution dependence of the tropopause inversion layer in an idealized model for upper-tropospheric anticyclones. J Atmos Sci 66:3491-3497

McIntyre ME (2009) Spontaneous imbalance and hybrid vortex-gravity structures. J Atmos Sci 66:1315-1326

Miyazaki K, Watanabe S, Kawatani Y, Sato K, Tomikawa Y, Takahashi M (2010a) Transport and mixing in the extratropical tropopause region in a high-vertical-resolution GCM. Part II: relative importance of large-scale and small-scale dynamics. J Atmos Sci 67:1315-1336

Miyazaki K, Watanabe S, Kawatani Y, Tomikawa Y, Takahashi M, Sato K (2010b) Transport and mixing in the extratropical tropopause region in a high-vertical-resolution GCM. Part I: potential vorticity and heat budget analysis. J Atmos Sci 67:1293-1314

Nakanishi M, Niino H (2004) An improved Mellor-Yamada Level-3 model with condensation physics: its design and verification. Boundary Layer Meteorol 112:1-31

Nakanishi M, Niino H (2006) An improved Mellor-Yamada Level-3 model: its numerical stability and application to a regional prediction of advection fog. Boundary Layer Meteorol 119:397-407

O'Sullivan D, Dunkerton TJ (1995) Generation of inertia-gravity waves in a simulated life cycle of baroclinic instability. J Atmos Sci 52:3695-3716

Plougonven R, Snyder C (2007) Inertia-gravity waves spontaneously generated by jets and fronts Part I: different baroclinic life cycles. J Atmos Sci 64:2502-2520

Randel WJ, Wu F (2010) The polar summer tropopause inversion layer. J Atmos Sci 67:2572-2581

Randel WJ, Wu F, Forster P (2007) The extratropical tropopause inversion layer: global observations with GPS data, and a radiative forcing mechanism. J Atmos Sci 64:4489-4496

Saito K, Fujita T, Yamada Y, Ishida J, Kumagai Y, Aranami K, Ohmori S, Nagasawa R, Kumagai S, Muroi C, Kato T, Eito H, Yamazaki Y (2006) The operational JMA nonhydrostatic mesoscale model. Mon Weather Rev 134:1266-1298

Saito K, Ishida J, Aranami K, Hara T, Segawa T, Narita M, Honda Y (2007) Nonhydrostatic atmospheric models and operational development at JMA. J Meteor Soc Japan 85B:271-304

Sanders F, Gyakum JR (1980) Synoptic-dynamic climatology of the "bomb". Mon Weather Rev 108:1589-1606

Skamarock WC (2004) Evaluating mesoscale NWP models using kinetic energy spectra. Mon Weather Rev 132:3019-3032

Son S-W, Polvani LM (2007) Dynamical formation of an extra-tropical tropopause inversion layer in a relatively simple general circulation model. Geophys Res Lett 34:17806. doi:10.1029/2007GL030564

Son S-W, Tandon NF, Polvani LM (2011) The fine-scale structure of the global tropopause derived from COSMIC GPS radio occultation measurements. J Geophys Res 116:20113. doi:10.1029/2011JD016030

Tomikawa Y, Nishimura Y, Yamanouchi T (2009) Characteristics of tropopause and tropopause inversion layer in the polar region. SOLA 5:141-144 
Wirth V (2003) Static stability in the extratropical tropopause region. J Atmos Sci 60:1395-1409

Wirth V (2004) A dynamical mechanism for tropopause sharpening Meteorologische Zeitschrift 13:477-484

Wirth V, Szabo T (2007) Sharpness of the extratropical tropopause in baroclinic life cycle experiments. Geophys Res Lett 34:02809. doi:10.1029/2006GL028369

Yabu S, Murai S, Kitagawa H (2005) Numerical Weather Prediction Division Report. Numerical Weather Prediction Division, Japan Meteorological Agency, Tokyo, Japan, pp 53-64. (in Japanese)

Zängl G, Wirth V (2002) Synoptic-scale variability of the polar and subpolar tropopause: data analysis and idealized PV inversions. Quart J Roy Meteor Soc 128:2301-2315

Zhang F (2004) Generation of mesoscale gravity waves in upper-tropospheric jet-front systems. J Atmos Sci 61:440-457

Zülicke C, Peters D (2006) Simulation of inertia-gravity waves in a poleward-breaking Rossby wave. J Atmos Sci 63:3253-3276

doi:10.1186/s40645-014-0019-0

Cite this article as: Otsuka et al:: A numerical experiment on the formation of the tropopause inversion layer associated with an explosive

cyclogenesis: possible role of gravity waves. Progress in Earth and Planetary Science 2014 1:19.

\section{Submit your manuscript to a SpringerOpen ${ }^{\circ}$ journal and benefit from:}

- Convenient online submission

- Rigorous peer review

- Immediate publication on acceptance

- Open access: articles freely available online

- High visibility within the field

- Retaining the copyright to your article

Submit your next manuscript at $\gg$ springeropen.com 